\title{
SISTEM PENDIDIKAN ISLAM BERWAWASAN MULTIKULTURAL Di NEGARA NEgARA ASEAN (MALAYSIA, FILIPINA, SINGAPURA DAN BRUNEI DARUSSALAM)
}

\author{
ROSSI DELTA FITRIANAH
}

\begin{abstract}
In the world of education, multicultural discourse is a relatively new phenomenon. Multicultural education began to be known after World War II. In other words multicultural education is a new symptom in the association of humanity who longs for equal rights, including the right to get the same education, for all people (education for all). Southeast Asia has its own history that is rich in diversity and participation. Some Western researchers describe the West as a carrier of pluralist world tolerance, Western Imperialism will have a direct influence on the four Southeast Asian societies, namely the deterioration and rigidity of ethnoreligious differences such as those in West Colonial.
\end{abstract}

Kata Kunci: Pendidikan Islam, Multikultural, Negara Asean.

\section{A. Pendahuluan}

Asia Tenggara memiliki sejarah tersendiri yang kaya kebhinekaan dan partisipasi. Beberapa peneliti Barat menggambarkan Barat sebagai pembawa toleransi pluralis dunia, Imperialisme Barat akan berpengaruh langsung di keempat masyarakat Asia Tenggara yaitu dengan memburuknya dan kakunya perbedaan-perbedaan etnoreligius seperti di Colonial Barat.

Diantara idealitas keagamaan Islam sebagaimana tertulis dalam al Qur'an adalah untuk saling mengenal dan menghormati berbagai budaya dan ras dan agama sebagai suatu realitas kemanusiaan akan tetapi pada saat yang sama peta dunia diwarnai konflik akibat SARA kesenjangan anatar idealitas dan realitas itulah yang perlu dijembatani dengan memberikan pemahaman multikultural dalam proses pendidikan keislaman. ${ }^{1}$ 
Multikulturalisme, sebagai sebuah diskursus, memang merupakan produk kajian ilmuan Barat akan realitas-eksistensial kebudayaan mereka yang heterogen. Namun, ke-khas-an kajian mereka tidak menyentuh aspek-aspek teologis, jika tidak mau disebut Agama²

Dalam dunia pendidikan, wacana multikultural merupakan fenomena relatif baru. Pendidikan multikultural mulai dikenal setelah perang Dunia II. Dengan kata lain pendidikan multikultural merupakan gejala baru dalam pergaulan umat manusia yang mendambakan persamaan hak, termasuk hak untuk mendapatkan pendidikan yang sama, untuk semua orang (education for all).

Pendidikan berwawasan multikulturalisme ini haruslah melekat dalam kurikulum dan strategi pengajaran, termasuk juga dalam setiap interaksi yang dilakukan diantara para guru, murid dan keluarga serta keseluruhan suasana belajar mengajar. Karena jenis pendidikan ini merupakan pedagogi kritis, refleksi dan menjadi basis aksi perubahan dalam masyarakat, pendidikan multikulturalisme mengembangkan prisip-prinsip demokrasi dalam berkeadilan sosial. ${ }^{3}$ Dari berbagai konsep tentang multikultural diatas berikut akan dibahas bagimana sistem pendidikan Islam berwawasan multikultural dinegara negara Asean (Malaysia, Singapura, Brunei Darussalam dan Filipina) secara komrehensip.

\section{B. Pembahasan}

1. Sistem PENDIDIKAN ISLAM BERWAWASAN MULTIKULTURAL DI MALAYSIA

Malaysia adalah negara yang memiliki keragaman budaya yang plural dan heterogen.Malaysia merupakan negara persemakmuran Inggris yang memilikikeragaman etnis, agama, dan budaya.Malaysia dan Indonesia merupakan saudara satu rumpun yang memiliki banyak 
persamaan.Keanekaragaman etnis, agama, dan budaya merupakan sedikit bentuk persamaan antara Malaysia dengan Indonesia.

Meskipun pluralisme, masyarakat Malaysia tetap menggunakan bahasa yang sama dalam bermasyarakat yaitu bahasa Melayu.Bahasa yang digunakan di Negara Malaysia adalah bahasa Melayu. Seperti negara-negara lain yang memiliki Bahasa Nasional, di Malaysia bahasa yang menjadi bahasa resminya adalah bahasa Melayu.Dengan keanekaragaman budaya yang berbeda, bahasa Melayu sebagai bahasa resmi di Malaysia pun dapat diterima oleh rakyatnya.

Pada sistem pemerintahan dan politiknya yang mendominasi jalannya roda pemerintahan adalah orang Malaysia yang diikuti oleh orang Cina, India, dan hanya sedikit sekali orang asli Malaysia. Hanya sedikitnya orang asli yang berada di kursi pemerintahan disebabkan orang asli yang masih sangat minim pendidikan dan berada di pedalaman yang kurang mendapat perhatian dari pemerintah.Sistem perpolitikan di Malaysia juga masih didominasi oleh orang Melayu, dimana semua partai politik yang sukses di Malaysia dibangun di sepanjang garis-garis etnis. Sebagaimana telah diamati oleh Milne dan Mauzy (1999: 18), sistem Malaysia itu merupakan semacam hegemonic consociationalism, di mana orang Melayu menikmati keunggulankeunggulan yang secara konstitusional disakralkan untuk warga negara non-Melayu .

Terdapat dua organisasi politik yang sangat terkemuka dan memiliki pendukung yang sangat banyak di Malaysia, yaitu UMNO (United Malays National Organisation) dan PAS (Postsecondary Agricultural Student Organization).Kedua organisasi politik ini memiliki paham yang berbeda. Meskipun keduanya merupakan berlandaskan atas islam, namun paham yang dianut bersebrangan satu sama lain.4Organisasi-organisasi politik yang berlandaskan islam ini telah 
memberikan dampak yang mengarah kepada etnoreligius. Abdul Rahman Embong dalam mengungkapkan bahwa dampak yang terjadi sangatsignifikan pada kebijaksanaan-kebijaksanaan negara dan perjuanganperjuangan, pada kehidupan sehari-hari rakyat, dan pada hubungan-hubungan etnis. Bahkan kelompok islam telah berusaha merancang institusi-institusi alternatif dalam nama islam, dengan mendirikan antara lain, institusi-institusi pendidikan dan pusat-pusat kesehatan mereka sendiri.

Pada bidang pendidikan di Malaysia ruang-ruang linguistik,

Dengan kemajuan yang mengesankan dalam bidang pendidikan, infrastruktur, dan penghapusan kemiskinan pada akhir 1990-an, Malaysia tampak contoh yang mengikilap tentang sebuah masyarakat dewasa yang membutuhkan sebuah politik sipil untuk mengesolidasikan kemajuan social dan ekonominya.

\section{Sistem PENDIDIKAN ISLAM BERWAWASAN MULTIKULTURAL DI SINGAPURA}

Singapura merupakan negara kecil yang berada di ujung Semenanjung Tanah Melayu. Dari awal mulanya, Singapura adalah sebuah kota imigran dari negara-negara lain, baik China, Malaysia, India dan Indonesia. Dari banyaknya etnis sehingga muncul suatu kepercayaan yang berbeda.

Muslim Singapura-secara politis-tergolong minoritas yang hidup di tengah masyarakat plural dan multi-kultural. Sejak kolonialisasi Inggris, keragaman etnis, budaya, dan agama semakin tampak jelas di negara ini sebagai konsekuensi dari lajunya arus migrasi terutama dari etnis Cina.Selain itu, arus modernisasi dan pembangunan yang begitu pesat serta ekonomi global modern yang berlangsung di negara ini memerlukan tenaga kerja yang handal dan profesional di bidangnya. ${ }^{4}$ 
Hal ini menjadi salah satu faktor penyebab lajunya arus migrasi tenaga kerja dari berbagai belahan dunia ke negara ini, sehingga semakin menambah keragaman etnis, budaya, dan agama (pluralitas dan multikultural) warga Singapura Selain itu, bila dilihat dari hubungan negara dan agama, Singapura dikenal sebagai negara sekular, di mana negara menjadi netral dalam permasalahan agama; tidak mendukung orang beragama Agama menjadi urusan pribadi, pemerintah tidak memiliki hak dan kewajiban untuk mengatur agama setiap individu.Paham sekularisme pemerintah berimplikasi pada beberapa kebijakan. Misalnya, suara azan yang berfungsi sebagai pengingat dan pemanggil Muslim untuk mendirikan shalat, tidak boleh dikumandangkan melalui loud speaker.

\section{Sistem PENDidikAN ISLAM BERWAWASAN MULTIKULTURAL DI BRUNEI DARUSSALAM}

Brunei Darussalam merupakan salah satu negara di kawasan Asia Tenggara yang terkenal sangat makmur.Brunei Darussalam yang merupakan anggota ke-6 ASEAN ini mendapatkan kemerdekaannya dari Inggris pada tanggal 1 Januari 1984.Sejak tahun 1984 Negara Brunei Darussalam telah memperkenalkan dasar pendidikan dwibahasa bagi menjamin pelajar berkebolehan dalam menguasai kedua-dua bahasa yaitu bahasa Melayu dan bahasa Inggeris.Manakala bahasa Inggeris pula digunakan bagi mengajar mata pelajaran seperti Sains, Matematik, Geografi, Sejarah, dan Bahasa Inggeris itu sendiri.

Program pendidikan diarahkan untuk menciptakan manusia yang berakhlak dan beragama dan menguasi teknologi. Pemerintah telah menetapkan tiga bidang utama dalam pendidikan, yaitu Sistem dwibahasa di semua sekolah, Konsep Melayu Islam Beraja (MIB) dalam kurikulum sekolah, peningkatan serta perkembangan sumber daya manusia termasuk pendidikan vokasional (kejuruan) dan teknik. 
Persekolahan di peringkat rendah hinggalah universiti bagi sekolahsekolah kerajaan adalah percuma bagi rakyat dan penduduk tetap Brunei

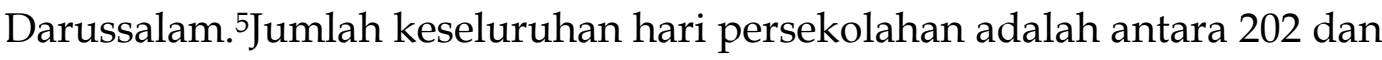
210 hari setahun.Terdapat empat (4) penggal persekolahan sepanjang persekolahan antara Januari hingga Desember. Sehingga tahun 2001 kadar kenal huruf di Negara Brunei Darussalam berada pada tahap 92.5\%.

\section{Sistem PENDidikAN ISLAM BERWAWASAN MUltikUltural DI FILIPINA}

Masuknya Islam di Filipina diperkirakan pada abad ketiga belas masehi. Namun, ada juga pendapat bahwa masuknya Islam ke Filipina berkisar antara abad ke-9 dan 15 Masehi dibawa oleh para aulia dan pedagang. Filipina terdiri dari 7.109 pulau dengan luas wilayah 29.062.000 hektar, dihuni oleh penduduk mayoritas beragama katolik. Penduduk muslim, menurut sensus tahun 1980 ada sejumlah 3,5 juta atau sekitar 7\% dari populasi penduduk Filipina. Menurut sensus penduduk tahun 1990 penduduk muslim di Filipina berjumlah 5\% dari totalitas penduduknya seluruhnya yakni sekitar 2,8 juta jiwa.

Penduduk muslim di Filipina terkonsentrasi di bagian selatan Filipina, terutama di Mendanau, Ujung Selatan Palawani, gugusan Kepulauan Sulu. Mereka terdiri dari tiga belas kelompok bahasa dan budaya, yaitu: Maranoa, Iranum, Maguindanao, Tausugs Samal, Bajao, Jama Mapun, Palawani, Malbog, kalibugan, Yakan, Karaza, dan Sangil. Di antara mereka itu ada tiga kelompok terbesar, yaitu Maranaos, Tausugs, dan Magu Indanoas. Decasa dalam Haidar Putra Daulay mengemukakan bahwa Islam telah dikenal di Sulu pada abad ke-13. Islam dikembangkan lewat jalur perdagangan dan juga disebarkan oleh para da'i yang Filipina Selatan dikenal dengan istilah Masaikh, Makdumin, dan Aulia. 
Di Filipina, pendidikan formal pada tingkat dasar dan menengah di sebut dengan maktab dan madrasah. Pendidikan maktab lebih dikhususkan pada pendidikan anak-anak usia 6 sampai 10 tahun. Para orang tua membawa anak-anak mereka baik laki-laki maupun perempuan ke rumah seorang muslim yang dituakan dan memiliki reputasi dalam bacaan Al-Qur'an. Selain dari lembaga pendidikan tersebut, di Filipina juga muncul lembaga pendidikan pola Barat ketika orang-orang Barat datang ke Filipina. Sekolah-sekolah Barat bersifat sekuler. Sebagai implikasi dari pemikiran dan budaya yang memisahkan agama dan negara. Keadaan ini bertentangan dengan doktrin keislaman. Madrasah dimulai dengan sebuah rumah yang sederhana yang diistilahkan dengan maktab, di tempat seorang guru, biasanya seorang pemimpin Islam mengajar sebuah grup kecil anak-anak, yang selanjutnya lembaga ini menempati posisi sebagai sekolah pandita (Pandita School).

Pengintegrasian madrasah ke sistem pendidikan di Filipina telah dilaksanakan pada tahun 1982. Madrasah mendapat pengakuan dari Menteri Pendidikan, Kebudayaan, dan Olahraga (The Ministry of Education, Cultural, and Sport) disingkat dengan MECS. Dengan masuknya madrasah ke dalam sistem pendidikan Filipina, maka pemerintah melaksanakan kegiatan:

a. Memperbaiki staf pengajar, dan fasilitas lembaga madrasah.

b. Memperkuat dan mengembangkan program Islamic Studies diberbagai lembaga pendidikan tinggi, khususnya di Mindanao,

c. Memperkuat dan mendirikan program pengajaran dan pembelajaran Bahasa Arab. 


\section{PENUTUP}

Dari seluruh rangkaian penelitian tentang Pendidikan Agama Islam berwawasan Multikulturalisme, maka penulis menyimpulkan bahwa : Islam adalah agama universal yang menjunjung tinggi nilai-nilai kemanusiaan, persamaan hak dan mengakui adanya keragaman latar belakang budaya dan kemajemukan. Multikultural menurut Islam adalah sebuah aturan Tuhan (sunnatullah) yang tidak akan berubah, juga tidak mungkin dilawan atau diingkari. Setiap orang akan menghadapi kemajemukan di manapun dan dalam hal apapun.Ungkapan ini menggambarkan bahwa Islam sangat menghargai multikultural karena Islam adalah agama yang dengan tegas mengakui perbedaan setiap individu untuk hidup bersama dan saling menghormati satu dengan yang lainnya.

Konsep multikulturalisme menekankan keanekaragaman kebudayaan dalam kesederajatan. Ulasan mengenai multikulturalisme akan mengulas berbagai permasalahan yang mendukung ideologi ini, yaitu politik dan demokrasi, keadilan dan penegakkan hukum, kesempatan kerja dan berusaha, Hak Asasi Manusia, hak budaya komuniti dan golongan minoritas, prinsip-prinsip etika dan moral, dan tingkat serta mutu produktivitas. Di dalam perkembangannya multikulturalisme telah mengambil dua bentuk yaitu: pertama, kebutuhan akan pengakuan di dalam masyarakat (the need of recognition) dan yang kedua ialah hak untuk berbeda (the rights to difference). Konsep multikulturalisme harus dikembangkan dan diinternalisasikan dalam proses transformasi nilai-nilai masyarakat dan bangsa yang beragam. Sarana terbaik dan strategis yang digunakan untuk membangun dan mensosialisasikan konsep multikulturalisme agar melahirkan perilaku sosial kondusif, kearifan sosial, kearifan budaya dan kearifan moral atau akhlak melalui pendidikan multikulturalisme yang merupakan sebuah 
prosedur (metode) untuk melembagakan (instutisionalisasi) filosofi kebinekaan budaya di sekolah.

Penulis : Rossi Delta Fitrianah, M.Pd adalah Dosen Tetap pada Fakultas Tarbiyah dan Tadris IAIN Bengkulu

\section{DAFTAR PUSTAKA}

Abd. Rachman, Assegaf. 2003. Internasional Pendidikan. Gama Media: Yogyakarta.

Banks,James, Multicultural Education;Issues and Persfectives, London:Allynand Baconpress,1989

Bikhu Parekh,Rethinking Multiculturalism: Cultural Diversity and Political Theory". American Journal of Sociology. 108 (3): 726728.doi:10.1086/378450

Jamil, Al-Sufri dkk. 2008. Satu Pemikiran Mengenai Corak Pendidikan untuk Brunei Darussalam Berasaskan Islam: Melalui Pengalaman dan Sejarah. Pusat Sejarah: Brunei Darussalam.

Munzir Hitami, 2006, "Sejarah Islam Asia Tenggara”, Alaf Riau, Pekanbaru

Nieto, Sonia.Language Culture and Teaching Najwal NJ: Lawrance Earlbaum,2002

SuzainaKadir.(2004). “Islam,State,andSocietyin Singapore”.InterAsiaCulturalStudies.Vol.5 Number 3.2004.

Tri Astuti, Islam dan Pendidikan Multikultural, STAIN Pekalongan . Jurnal tadris vol4

Zuhairini, dkk. 1994, Sejarah Pendidikan Islam, Jakarta :Bumi Aksara 
${ }^{1}$ Tri Astuti, Islam dan Pendidikan Multikultural, STAIN Pekalongan . Jurnal tadris vol4

${ }^{2} Z$ uhairini, dkk. 1994, Sejarah Pendidikan Islam, Jakarta :Bumi Aksara

${ }^{3}$ Abd. Rachman, Assegaf. 2003. Internasional Pendidikan. Gama Media: Yogyakarta.

4SuzainaKadir.(2004).“Islam,State,andSocietyinSingapore”.Inter-

AsiaCulturalStudies.Vol.5 Number 3.2004.

5Jamil, Al-Sufri dkk. 2008. Satu Pemikiran Mengenai Corak Pendidikan untuk Brunei Darussalam Berasaskan Islam: Melalui Pengalaman dan Sejarah. Pusat Sejarah: Brunei Darussalam. 